\title{
ISOTHERMAL MODELS OF CHROMIUM (VI) ADSORPTION BY USING $\mathrm{Fe}_{3} \mathrm{O}_{4}$ NANOPARTICLES
}

\author{
Dang Tan Hiep ${ }^{1}$, Bui Thi Hoa ${ }^{2,3}$, Ngo Thi My Thanh ${ }^{4}$, Nguyen Anh Tien $^{5}$, \\ Nguyen Viet Long ${ }^{6}$, Le Hong Phuc ${ }^{7}$, Bui Xuan Vuong ${ }^{8,9 *}$ \\ ${ }^{1}$ Faculty of Chemical Engineering, Ho Chi Minh City University of Food Industry, \\ Ho Chi Minh City, 700000, Vietnam \\ ${ }^{2}$ Institute of Theoretical and Applied Research, Duy Tan University, Hanoi, \\ 100000, Vietnam \\ ${ }^{3}$ Faculty of Natural Sciences, Duy Tan University, Da Nang, 550000, Vietnam \\ ${ }^{4}$ Faculty of Chemical Technology and Food, Ho Chi Minh City Industry and Trade \\ College, 20 Tang Nhon Phu, District 9, Ho Chi Minh City, 700000, Vietnam \\ ${ }^{5}$ Faculty of Chemistry, Ho Chi Minh City University of Education, \\ Ho Chi Minh City, 700000, Vietnam \\ ${ }^{6}$ Department of Electronics and Telecommunication, Sai Gon University, \\ 273 An Duong Vuong, District 5, Ho Chi Minh City, 700000, Vietnam \\ ${ }^{7}$ Ho Chi Minh City Institute of Physics, Vietnam Academy of Science and Technology, \\ 01 Mac Dinh Chi St, District 01, Ho Chi Minh City, 700000, Vietnam \\ ${ }^{8}$ Department for Management of Science and Technology Development, \\ Ton Duc Thang University, Ho Chi Minh City, 700000, Vietnam \\ ${ }^{9}$ Faculty of Applied Sciences, Ton Duc Thang University, Ho Chi Minh City, 700000, \\ Vietnam
}

Received 06.04.2020

Accepted 22.06.2020

\begin{abstract}
The ferromagnetic $\mathrm{Fe}_{3} \mathrm{O}_{4}$ nanoparticles with the average particle size of about 10 $\mathrm{nm}$ were used to adsorb chromium (VI) in aqueous solution. The equilibrium of $\mathrm{Cr}(\mathrm{VI})$ adsorption can be achieved at the $\mathrm{pH}$ value of 2.5 , in the contact time of 120 minutes. The mechanisms of $\mathrm{Cr}(\mathrm{VI})$ adsorption were evaluated by 4 isothermal adsorption models Langmuir, Freundlich, Redlich-Peterson, and Temkin. The results showed that all four models are satisfied; especially, Redlich-Peterson is the most suitable model to describe the adsorption kinetic of $\mathrm{Cr}(\mathrm{VI})$ on ferromagnetic $\mathrm{Fe}_{3} \mathrm{O}_{4}$ nanoparticles.
\end{abstract}

Keywords: $\mathrm{Fe}_{3} \mathrm{O}_{4}$ ferromagnetic nanoparticles, adsorption, $\mathrm{Cr}(\mathrm{VI})$, equilibrium, Redlich-Peterson.

${ }^{*}$ Corresponding author: Bui Xuan Vuong, buixuanvuong@tdtu.edu.vn 


\section{Introduction}

Industrial activities such as mining, processing and metallurgy, electroplating, tanning, texturing, and dyeing are the main causes leading to the accumulation of chromium in the environment [1-2]. In water, chromium normally exists in various forms such as $\mathrm{Cr}(\mathrm{III})\left(\mathrm{Cr}^{3+}, \mathrm{Cr}(\mathrm{OH})^{2+}\right)$ and $\mathrm{Cr}(\mathrm{VI})\left(\mathrm{HCrO}^{4-}, \mathrm{CrO}_{4}{ }^{2-}, \mathrm{Cr}_{2} \mathrm{O}_{7}{ }^{2-}\right)$, in which $\mathrm{Cr}(\mathrm{VI})$ is listed as one of the most 20 pollutants endangering human health [3]. Chromium (VI) can cause allergies, dermatitis, liver damage, and extremely dangerous diseases like cancer [3]. Currently, many chemical and physical methods have been used to remove $\mathrm{Cr}(\mathrm{VI})$ ions in water environments such as adsorption, ion exchange, dialysis, coagulation, precipitation, and separation [4-6]. Among them, the adsorption method is one of the most convenient, economical, and effective. In the literature, metal-organic frameworks (MOF) such as copper benzene 1,3,5-tricarboxylate (Cu-BTC) was used to remove $\mathrm{Cr}(\mathrm{VI})$ ions in aqueous solution with an adsorption capacity of $48.0 \mathrm{mg} / \mathrm{g}$ [7]. Composite of fly ash/chitosan experimentally adsorbed $\mathrm{Cr}(\mathrm{VI})$ with an adsorption capacity of 36.2 $\mathrm{mg} / \mathrm{g}$ [8]. Melamine-formaldehyde resin with medium capillary structure was an interesting absorbed material with very high adsorption capacity $(66.7 \mathrm{mg} / \mathrm{g})$ [9]. The nano-composite $\mathrm{BaTiO}_{3} @ \mathrm{SBA}-15$ showed a high adsorption efficiency with $98 \%$ of $\mathrm{Cr}(\mathrm{VI})$ removal in 40 minutes [10]. The surface-modified $\mathrm{MnFe}_{2} \mathrm{O}_{4}$ nanoparticles were efficient absorbent for fast removal of $\mathrm{Cr}(\mathrm{VI})$ from wastewater, with an interesting adsorption capacity of $31.5 \mathrm{mg} / \mathrm{g}$ [11]. The development of nanotechnology has opened up a variety of effective adsorbents to remove toxic heavy metal ions. Nano-materials can be easily synthesized at a low cost. Moreover, due to their small sizes and thus large specific surface areas, nanomaterials have strong adsorption capacities and reactivity [1213]. Typically, ferromagnetic $\mathrm{Fe}_{3} \mathrm{O}_{4}$ nanoparticle exhibits unique physical and chemical properties such as electronic structure change, large specific surface area and good adsorption capacity $[6,14]$. Thank magnetic properties, it can be easily separated and refined during the experiment. Depending on the synthesis process, ferromagnetic $\mathrm{Fe}_{3} \mathrm{O}_{4}$ and modified $\mathrm{Fe}_{3} \mathrm{O}_{4}$ nanoparticles show different morphologies of size and structure, resulting in different adsorption capacity [13-17].

In this study, ferromagnetic $\mathrm{Fe}_{3} \mathrm{O}_{4}$ nanoparticles with an average particle size of $10 \mathrm{~nm}$ were used to adsorb $\mathrm{Cr}(\mathrm{VI})$ in aqueous solution. The factors affecting the $\mathrm{Cr}(\mathrm{VI})$ adsorption such as $\mathrm{pH}$, contact time, and initial concentration of $\mathrm{Cr}(\mathrm{VI})$ solutions were investigated. The mechanisms of $\mathrm{Cr}(\mathrm{VI})$ adsorption onto ferromagnetic $\mathrm{Fe}_{3} \mathrm{O}_{4}$ nanoparticles were studied and evaluated by four isothermal adsorption models Langmuir, Freundlich, Redlich-Peterson, and Temkin.

\section{Materials and methods}

\section{Materials}

Iron (III) chloride hexahydrate $\left(\mathrm{FeCl}_{3} \cdot 6 \mathrm{H}_{2} \mathrm{O}, \geq 98 \%\right.$, Sigma-Aldrich); iron (II) chloride tetrahydrate $\left(\mathrm{FeCl}_{2} \cdot 6 \mathrm{H}_{2} \mathrm{O}, \geq 99 \%\right.$, Merck); ammonia solution $\left(\mathrm{NH}_{4} \mathrm{OH}, 25\right.$ $28 \%, 0.91 \mathrm{~g} / \mathrm{mL}$, Merck); potassium chromate $\left(\mathrm{K}_{2} \mathrm{CrO}_{4}, \geq 98 \%\right.$, Merck); 1,5diphenylcarbazide $\left(\mathrm{C}_{6} \mathrm{H}_{5} \mathrm{NHNHCONHNHC}_{5} \mathrm{H}_{6}, \geq 99 \%\right.$, Sigma-Aldrich); phosphoric acid $\left(\mathrm{H}_{3} \mathrm{PO}_{4}, 85 \%\right.$, Merck); sodium hydroxide $\left(\mathrm{NaOH}, \geq 99 \%\right.$, Merck); nitric acid $\left(\mathrm{HNO}_{3}\right.$, $70 \%$, Merck). 
Synthesis of ferromagnetic $\mathrm{Fe}_{3} \mathrm{O}_{4}$ nanoparticles

The $\mathrm{Fe}_{3} \mathrm{O}_{4}$ material was synthesized by dissolving a mixture of $\mathrm{FeCl}_{3}$ and $\mathrm{FeCl}_{2}$ in boiling water. The reaction system was stirred until the mixture was completely dissolved. Then, the $\mathrm{NH}_{4} \mathrm{OH}$ solution was quickly added to the reaction mixture and continued to stir for 10 minutes. After that, the precipitation was collected quickly by placing a magnet outside the beaker. The precipitation was washed with distilled water to remove residual ions from the mixture and then dried in a vacuum desiccator. Finally, the obtained crystals of $\mathrm{Fe}_{3} \mathrm{O}_{4}$ were ground to a fine powder.

\section{Experiments of $\mathrm{Cr}(\mathrm{VI})$ adsorption}

The $\mathrm{Cr}(\mathrm{VI})$ solutions were made by dissolving potassium chromate salt $\mathrm{K}_{2} \mathrm{CrO}_{4}$ in distilled water with concentrations of 20,40, 60, 80, 100, 120,140, 160, 180 and $200 \mathrm{mg} / \mathrm{L}$. The adsorption experiment was effectuated by immersing $0.1 \mathrm{~g}$ ferromagnetic $\mathrm{Fe}_{3} \mathrm{O}_{4}$ nanoparticles in $40 \mathrm{ml}$ of $\mathrm{Cr}(\mathrm{VI})$ solution. The mixture was stirred at $100 \mathrm{rpm}$, at room temperature of $32.2{ }^{\circ} \mathrm{C}$. The quantity of $\mathrm{Cr}(\mathrm{VI})$ in the solution before and after adsorption by ferromagnetic $\mathrm{Fe}_{3} \mathrm{O}_{4}$ nanoparticles was determined by measuring the absorbance of the red-violet complex formed by the reaction of $\mathrm{Cr}(\mathrm{VI})$ with 1 , 5-diphenylcarbazide in phosphoric acid at $544 \mathrm{~nm}$ on an atomic absorption spectrometer (AA-7000-Shimadzu). The adsorption efficiency $\mathrm{H}(\%)$ and the adsorption capacity $\mathrm{q}(\mathrm{mg} / \mathrm{g})$ are calculated by two following formulas:

$$
\begin{aligned}
& H \%=\frac{\left(C_{o}-C\right)}{C_{o}} .100 \\
& q=\frac{\left(C_{o}-C\right) V}{m}
\end{aligned}
$$

where $\mathrm{C}_{\mathrm{o}}$ and $\mathrm{C}(\mathrm{mg} / \mathrm{L})$ are the concentrations of $\mathrm{Cr}(\mathrm{VI})$ solution before and after adsorption, $\mathrm{V}(\mathrm{L})$ is the volume of $\mathrm{Cr}(\mathrm{VI})$ solution, $\mathrm{m}(\mathrm{g})$ is the mass of the ferromagnetic $\mathrm{Fe}_{3} \mathrm{O}_{4}$ adsorbent.

\section{Evaluation methods}

The crystalline structure of powdered nanoparticles was characterized by the XRD method, performed on XRD-D8 ADVANCE (Brucker, Germany). The size of the $\mathrm{Fe}_{3} \mathrm{O}_{4}$ nanoparticles was determined by the TEM method, using the JEM-1400-JEOL (Japan) equipment system. The specific surface area was checked by the BET method, using Nova station A equipment, version 9.0 (Quantachrome Firm). The quantity of $\mathrm{Cr}$ (VI) in the solution before and after adsorption by $\mathrm{Fe}_{3} \mathrm{O}_{4}$ nanoparticles was found out by measuring the absorbance of the red-violet complex formed by the reaction of chromium (VI) with 1,5-diphenylcarbazide in phosphoric acid at $544 \mathrm{~nm}$ on an atomic absorption spectrometer (AA-7000-Shimadzu).

\section{Results and discussion}

\section{Characterization of ferromagnetic $\mathrm{Fe}_{3} \mathrm{O}_{4}$ nanoparticles}

The crystallinity of synthesized $\mathrm{Fe}_{3} \mathrm{O}_{4}$ nanoparticles can be identified via XRD analysis. The XRD patterns of synthesized $\mathrm{Fe}_{3} \mathrm{O}_{4}$ nanoparticles are shown in Figure 1. The diffraction peaks of synthesized $\mathrm{Fe}_{3} \mathrm{O}_{4}$ were detected at $2 \theta=30^{\circ}, 36^{\circ}, 43^{\circ}, 57^{\circ}$, and $63^{\circ}$, which are assigned to the crystal planes of (220), (311), (400), (511), and (440), 
respectively (JCPDS file no. 75-0033). The strong and sharp peaks obtained from the $\mathrm{XRD}$ diagram confirmed the high crystallinity of ferromagnetic $\mathrm{Fe}_{3} \mathrm{O}_{4}$ nanoparticles. The size and morphology of the synthesized $\mathrm{Fe}_{3} \mathrm{O}_{4}$ nanoparticles were analyzed by using the TEM technique. The observation showed that $\mathrm{Fe}_{3} \mathrm{O}_{4}$ nanoparticles were in spherical shapes with an average size of about $10.0 \mathrm{~nm}$ (Figure 2).

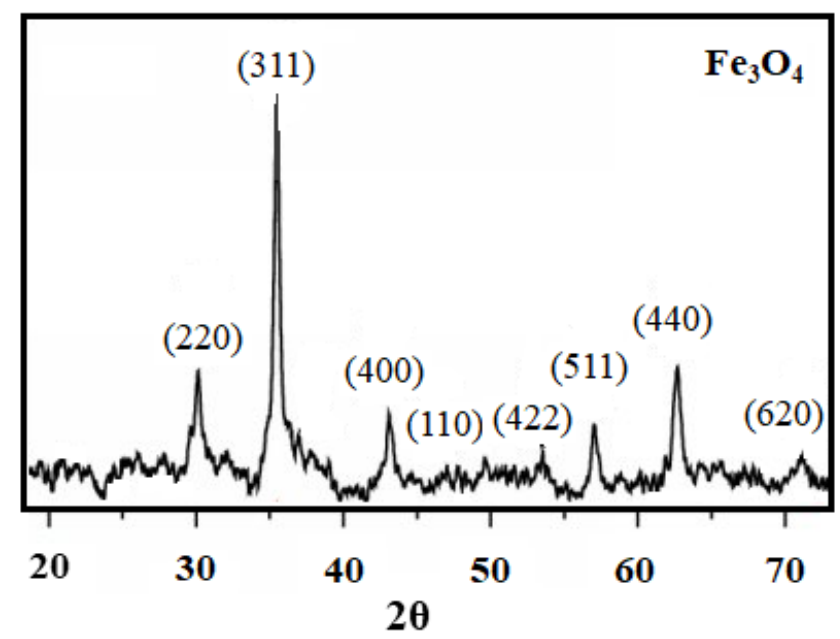

Fig. 1. XRD diagram of ferromagnetic $\mathrm{Fe}_{3} \mathrm{O}_{4}$ nanoparticles.

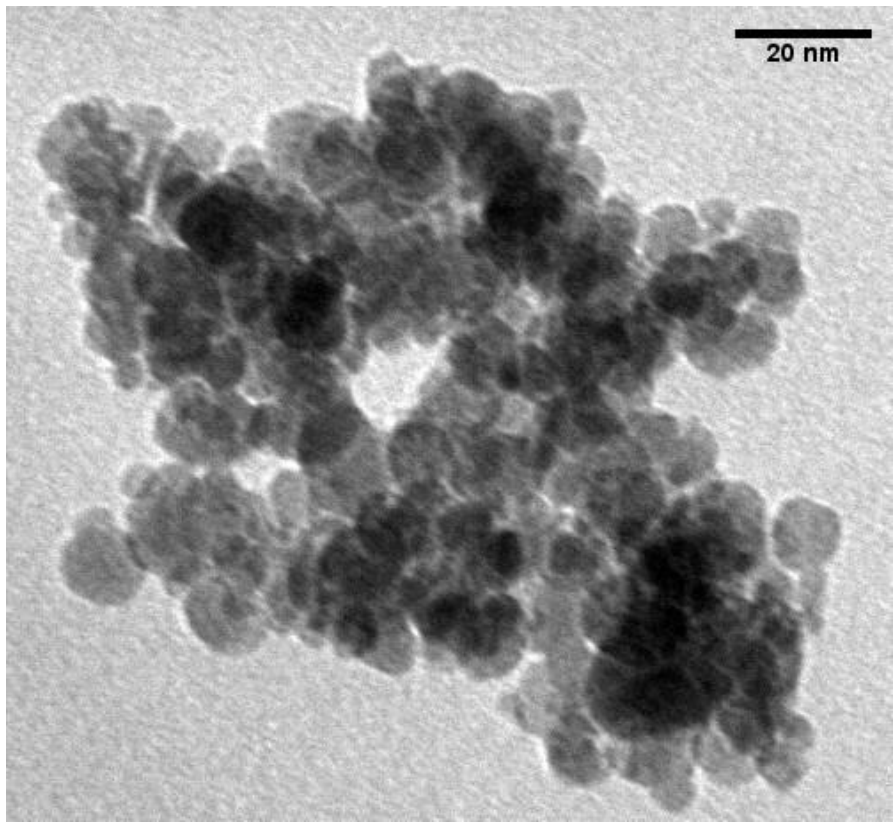

Fig. 2. TEM micrograph of ferromagnetic $\mathrm{Fe}_{3} \mathrm{O}_{4}$ nanoparticles. 


\section{Effect of pH on $\mathrm{Cr}(\mathrm{VI})$ adsorption by $\mathrm{Fe}_{3} \mathrm{O}_{4}$ nanoparticles}

In aqueous solution, the adsorption efficiency of ions such as metal cations and inorganic anions in free or complex forms was influenced by various factors such as the quantity of ion in solution, $\mathrm{pH}$, and other co-existing ions [18-19]. In particular, $\mathrm{pH}$ plays an important role relating to the adsorption mechanism. Based on $\mathrm{pH}$ value, physical and chemical interactions of substances in solution with active adsorbent centers can be interpreted. Figure 3 shows $\mathrm{Cr}(\mathrm{VI})$ adsorption efficiency at different $\mathrm{pH}$ from 2.0 to 10.0 . The best adsorption efficiency was achieved at a $\mathrm{pH}$ of $2.5(43.2 \%)$. Then, the adsorption efficiency decreased as increasing the $\mathrm{pH}$ value and rapidly decreased in the range of $\mathrm{pH}$ from 7 to 10. The surface charge of the adsorbent can explain the dependence of $\mathrm{Cr}(\mathrm{VI})$ adsorption efficiency on $\mathrm{pH}$. In general, the surface of metal oxides is covered with hydroxyl groups, which change at different $\mathrm{pH}$ ranges. At the isoelectric point $\mathrm{pH}_{\mathrm{pzc}}$, the surface charge will be neutral. According to the literature [20], ferromagnetic $\mathrm{Fe}_{3} \mathrm{O}_{4}$ has an isoelectric point around 6.5. At $\mathrm{pH}$ lower than $\mathrm{pH}_{\mathrm{pzc}}$, the adsorbent surface is a positive charge, and anionic adsorption will occur due to electrostatic attraction. In contrast, at $\mathrm{pH}$ higher than $\mathrm{pH}_{\mathrm{pzc}}$, the adsorbent surface is a negative charge, cationic adsorption appears. In the case of chromium (VI) adsorption, the adsorption efficiency decreases with increasing $\mathrm{pH}$, probably due to high concentrations of $\mathrm{OH}$ - ions, which will compete for adsorption centers with $\mathrm{Cr}(\mathrm{VI})$ in $\mathrm{CrO}_{4}{ }^{2-}$ solution. In other words, when the iron oxide surface is negatively charged $\left(\mathrm{pH}>\mathrm{pH}_{\mathrm{pzc}}\right)$, the electrostatic repulsion between adsorbed $\mathrm{HCrO}_{4}^{-}$and $\mathrm{CrO}_{4}{ }^{2-}$ ions with the adsorbent surface increases, the adsorption efficiency decreases.

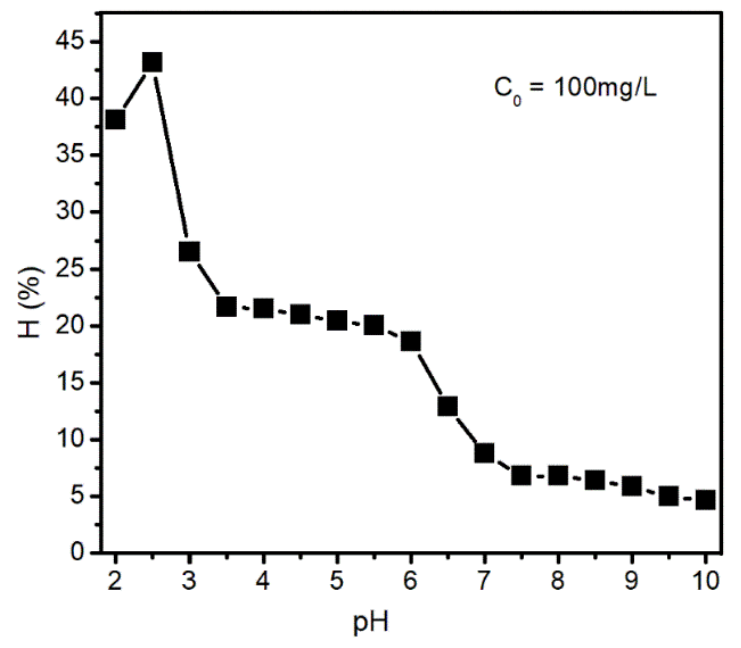

Fig. 3. Effect of pH on Cr(VI) adsorption efficiency $H(\%), C_{o}$ refers to the concentration of $\mathrm{Cr}(\mathrm{VI})$ solution before adsorption.

\section{Effect of time on Cr(VI) adsorption efficiency}

At an optimal value of $\mathrm{pH}, \mathrm{Cr}(\mathrm{VI})$ adsorption efficiency by ferromagnetic $\mathrm{Fe}_{3} \mathrm{O}_{4}$ nanoparticles at different times was investigated (Figure 4). The results presented that at the beginning, the adsorption rate significantly increased, and reached equilibrium status at $\mathrm{t}=120$ minutes. Therefore, 120 minutes is chosen as the time of adsorption equilibrium. 


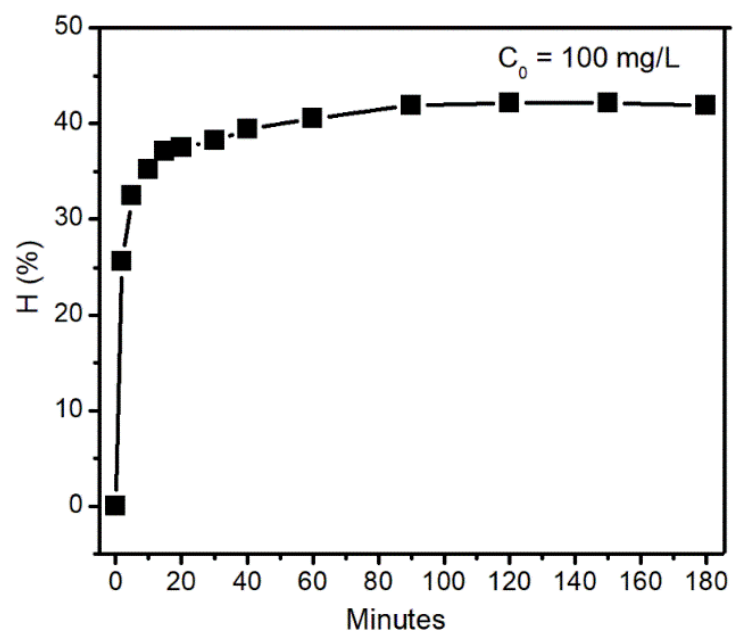

Fig. 4. Effect of time on Cr(VI) adsorption efficiency (H\%), $C_{o}$ refers to the concentration of the Cr(VI) solution before adsorption.

Equilibrium of $\mathrm{Cr}(\mathrm{VI})$ adsorption - Isothermal studies

Table 1. Adsorption parameters for isothermal models.

\begin{tabular}{lccccc}
\hline $\begin{array}{l}\mathrm{C}_{\mathrm{o}} \\
(\mathrm{mg} / \mathrm{L})\end{array}$ & $\begin{array}{c}\mathrm{C}_{\mathrm{e}} \\
(\mathrm{mg} / \mathrm{L})\end{array}$ & $\mathrm{LnC}_{\mathrm{e}}$ & $\begin{array}{c}\mathrm{q}_{\mathrm{e}} \\
(\mathrm{mg} / \mathrm{g})\end{array}$ & $\mathrm{Lnq}_{\mathrm{e}}$ & $\begin{array}{c}\mathrm{C}_{\mathrm{e}} / \mathrm{q}_{\mathrm{e}} \\
(\mathrm{g} / \mathrm{L})\end{array}$ \\
\hline 20 & 4.03 & 1.39 & 6.37 & 1.85 & 0.63 \\
40 & 9.64 & 2.27 & 12.15 & 2.50 & 0.79 \\
60 & 25.53 & 3.24 & 13.79 & 2.62 & 1.85 \\
80 & 41.89 & 3.74 & 15.18 & 2.72 & 2.76 \\
100 & 59.41 & 4.08 & 16.23 & 3.10 & 3.66 \\
120 & 76.71 & 4.34 & 17.28 & 2.85 & 4.44 \\
140 & 92.37 & 4.53 & 19.03 & 2.95 & 4.85 \\
160 & 109.19 & 4.69 & 20.24 & 3.00 & 5.40 \\
180 & 126.25 & 4.84 & 21.41 & 3.06 & 5.90 \\
200 & 142.38 & 4.96 & 23.00 & 3.14 & 6.19 \\
\hline
\end{tabular}

$\mathrm{C}_{0}(\mathrm{mg} / \mathrm{L})$ : initial concentration of $\mathrm{Cr}(\mathrm{VI})$ solution, $\mathrm{C}_{\mathrm{e}}(\mathrm{mg} / \mathrm{L})$ : equilibrium concentration of $\mathrm{Cr}(\mathrm{VI})$ solution, $\mathrm{q}_{\mathrm{e}}(\mathrm{mg} / \mathrm{g})$ : maximum adsorption capacity at equilibrium time.

The process of chromium adsorption on $0.1 \mathrm{~g}$ of ferromagnetic $\mathrm{Fe}_{3} \mathrm{O}_{4}$ was carried out at optimal $\mathrm{pH}=2.5$, room temperature $=32.2{ }^{\circ} \mathrm{C}$ and $\mathrm{t}=120$ minutes. The concentration of chromium solution was tested from 20 to $200 \mathrm{mg} / \mathrm{L}$. The volume of the chromium solution is $40 \mathrm{~mL}$. Adsorption parameters corresponding to the initial concentration of chromium solution was presented in Table 1. 
$\underline{\text { Langmuir isothermal adsorption model }}$

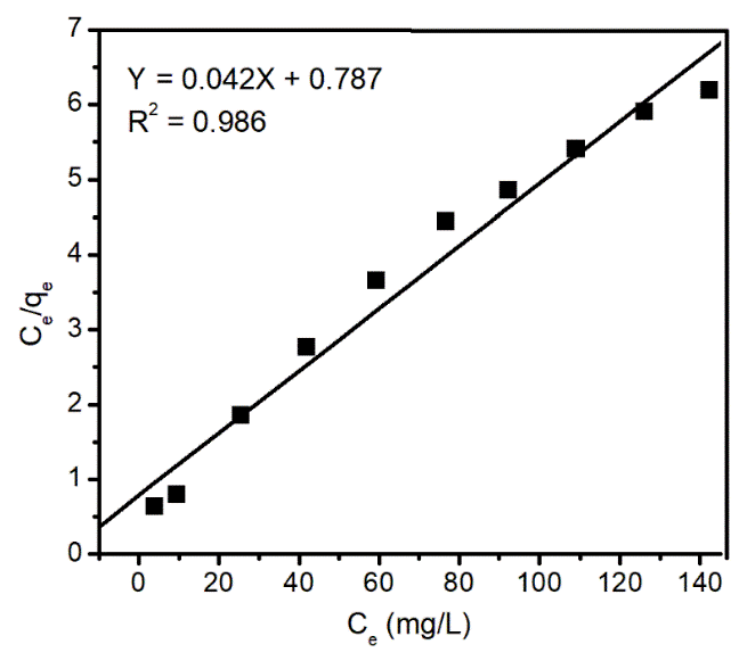

Fig. 5. Langmuir isothermal adsorption model, $C_{e}(\mathrm{mg} / \mathrm{L})$ : equilibrium concentration of $\mathrm{Cr}(\mathrm{VI})$ solution, $q_{e}(\mathrm{mg} / \mathrm{g})$ : maximum adsorption capacity at equilibrium time.

According to the Langmuir isothermal adsorption model, the adsorption of metal ions is assumed to occur on a homogeneous surface, monolayer surface of the adsorbent without any interaction between adsorbed ions [21]. A linear equation shows the Langmuir isothermal adsorption model:

$$
\frac{C_{e}}{q_{e}}=\frac{C_{e}}{q_{m}}+\frac{1}{K_{L} \cdot q_{m}}
$$

where $\mathrm{K}_{\mathrm{L}}$ is the Langmuir adsorption constant, $q_{m}$ is the maximum adsorption capacity.

The Langmuir isothermal adsorption model was shown in figure 5. The high value of the correlation coefficient $\left(\mathrm{R}^{2}=0.986\right)$ indicated that the Langmuir isothermal model is suitable for $\mathrm{Cr}(\mathrm{VI})$ adsorption by ferromagnetic $\mathrm{Fe}_{3} \mathrm{O}_{4}$ nanoparticles. The maximum adsorption capacity $q_{m}$ was $24.03 \mathrm{mg} / \mathrm{g}$, the Langmuir adsorption constant is 0.053 .

\section{Freundlich isothermal adsorption model}

According to the Freundlich isothermal adsorption model, the adsorption is assumed that adsorption occurs on the inhomogeneous surface of the material [21-22]. 
The following equation represents the linear equation:

$$
L n q_{e}=\operatorname{Ln} K_{F}+\frac{1}{n} \cdot \operatorname{Ln} C_{e}
$$

where $\mathrm{n}$ is the exponential constant in the Freundlich equation, which characterizes for heterogeneous energy of the adsorbed surface. $K_{F}$ is the Freundlich constant to show the relative adsorption capacity of adsorbent materials. The Freundlich model was chosen to evaluate the adsorption intensity of the adsorbate on the surface of the adsorbent. The graph of the Freundlich isothermal equation was shown in Figure 6.

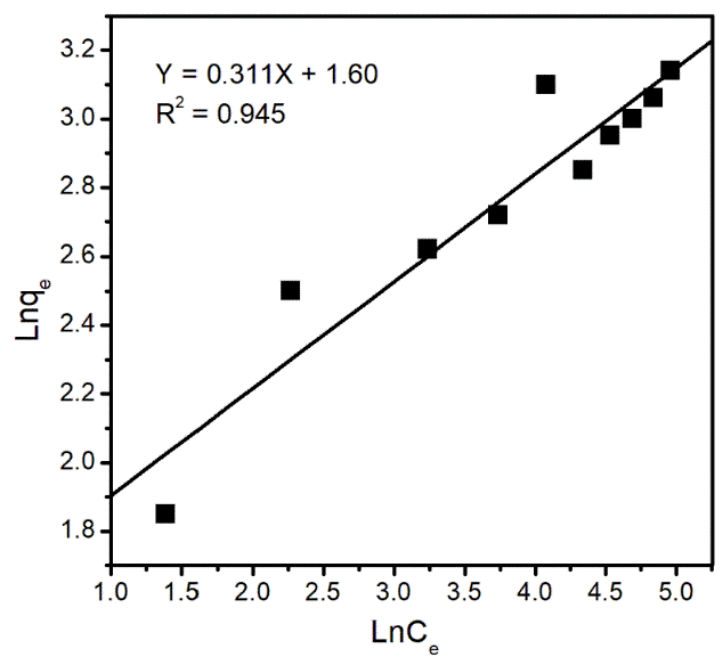

Fig. 6. Freundlich isothermal adsorption model, $C_{e}(\mathrm{mg} / \mathrm{L})$ : equilibrium concentration of $\mathrm{Cr}(\mathrm{VI})$ solution, $q_{e}(\mathrm{mg} / \mathrm{g})$ : maximum adsorption capacity at equilibrium time.

The value correlation coefficient $\mathrm{R}^{2}$ in the Freundlich model is lower than that in the Langmuir adsorption isothermal model. The value of $1 / \mathrm{n}$ in the case of adsorption on liquid/solid boundary is in the range of $0.1-0.5$ [22]. In this study, the calculated value of $1 / \mathrm{n}$ was 0.311 , showing a good fit for the above range, indicating that the Freundlich adsorption isothermal model can be used to describe the chromium (VI) adsorption process by ferromagnetic $\mathrm{Fe}_{3} \mathrm{O}_{4}$ nanoparticles.

Redlich-Peterson isothermal adsorption model

Redlich-Peterson isothermal adsorption model is an isothermal model combining Langmuir and Freundlich models [23]. The Redlich-Peterson equation is described as follows:

$$
\operatorname{Ln}\left(K_{R P} \frac{C_{e}}{q_{e}}-1\right)=\beta \operatorname{Ln} C_{e}+\operatorname{Ln} \alpha_{R P}
$$

where $\mathrm{K}_{\mathrm{RP}}(\mathrm{L} / \mathrm{g}), \alpha_{\mathrm{RP}}(\mathrm{L} / \mathrm{mg})$, and $\beta$ are constants. $\beta$ is in the range between 0 and 1. The Redlich-Peterson isothermal adsorption model accesses the Freundlich model at 
high concentration ( $\beta$ approaches to 0 ) and accesses the Langmuir model at low concentration ( $\beta$ approaches to 1$)$.

Chromium adsorption, according to the Redlich-Peterson isothermal adsorption model is shown in Figure 7. Linear correlation with high correlation coefficient $\mathrm{R}^{2}=$ 0.994 indicating that the Redlich-Peterson isothermal adsorption model is also suitable to describe the chromium adsorption on ferromagnetic $\mathrm{Fe}_{3} \mathrm{O}_{4}$ nanoparticles.

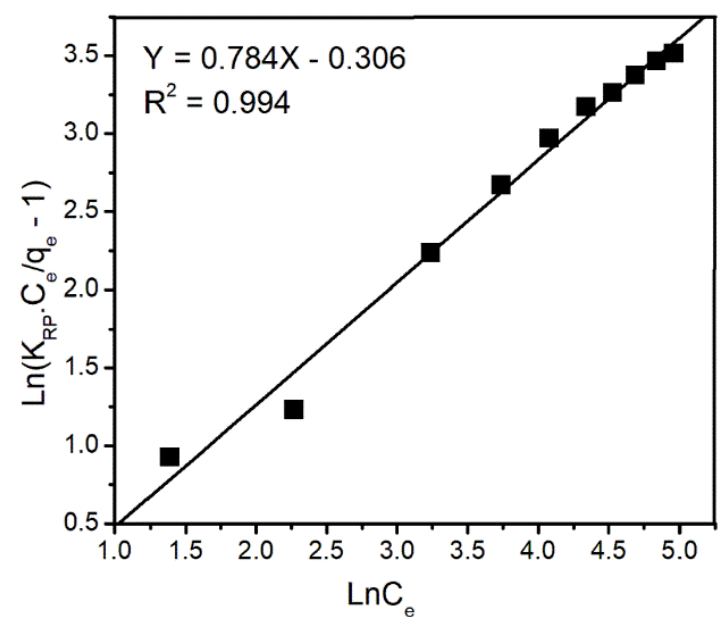

Fig. 7. Redlich-Peterson isothermal adsorption model, $K_{R P}$ is constant, $C_{e}(m g / L)$ : equilibrium concentration of $\mathrm{Cr}(\mathrm{VI})$ solution, $q_{e}(\mathrm{mg} / \mathrm{g})$ : maximum adsorption capacity at equilibrium time.

Temkin isothermal adsorption model

Temkin isothermal adsorption was used to apply for chemical adsorption [23]. This model shows that the heat energy of all molecules absorbed on the surface decreases linearly with the coverage area due to the interaction between adsorbent and adsorbate. The Temkin equation is described as follows:

$q_{e}=B \operatorname{Ln} K_{T}+B \operatorname{Ln} C_{e}$

where $\mathrm{B}=\mathrm{RT} / \mathrm{b}_{\mathrm{T}}, \mathrm{T}$ is the adsorption temperature (Kelvin), $\mathrm{R}$ is the gas constant $(8.314 .10-3 \mathrm{~kJ} / \mathrm{mol} \cdot \mathrm{K}), \mathrm{b}_{\mathrm{T}}$ is the Temkin constant $\left.\mathrm{kJ} / \mathrm{mol}\right)$. 
Figure 8 indicated $\mathrm{K}_{\mathrm{T}}=1.31(\mathrm{~L} / \mathrm{mg}), \mathrm{b}_{\mathrm{T}}=0.63(\mathrm{~mol} / \mathrm{kJ})$ and $\mathrm{R}^{2}=0.970$. Empirical data analysis indicated that all four isothermal adsorption models are suitable to describe chromium (VI) adsorption by ferromagnetic $\mathrm{Fe}_{3} \mathrm{O}_{4}$ nanoparticles, in which the RedlichPeterson model is the best fit.

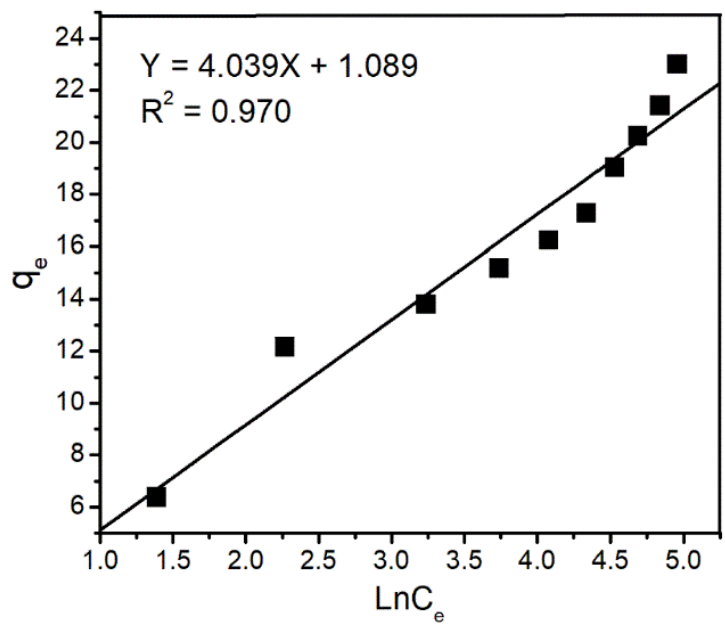

Fig. 8. Temkin isothermal adsorption model, $C_{e}(\mathrm{mg} / \mathrm{L})$ : equilibrium concentration of $\mathrm{Cr}(\mathrm{VI})$ solution, $q_{e}(\mathrm{mg} / \mathrm{g})$ : maximum adsorption capacity at equilibrium time.

\section{Conclusion}

This study investigated chromium (VI) adsorption on ferromagnetic $\mathrm{Fe}_{3} \mathrm{O}_{4}$ nanoparticles in aqueous solution. The factors affecting $\mathrm{Cr}(\mathrm{VI})$ adsorption such as $\mathrm{pH}$, exposure time, and initial concentration of $\mathrm{Cr}(\mathrm{VI})$ solutions, were evaluated. Experimental data were analyzed by 4 isothermal adsorption models Langmuir, Freundlich, Redlich-Peterson, and Tempkin. The results show that in the optimal conditions $(\mathrm{pH}=2.5$, stirring speed $=100 \mathrm{rpm}$, stirring time $=120$ minutes, adsorbent mass $\mathrm{Fe}_{3} \mathrm{O}_{4}=0.1$ grams), the $\mathrm{Cr}(\mathrm{VI})$ adsorption process can be well fitted by all 4 isothermal models. Interestingly, the Redlich-Peterson model shows the best suitability for chromium (VI) adsorption with a very high correlation coefficient $\left(\mathrm{R}^{2}=0.994\right)$. 


\section{References}

[1] Y. Wang, J. Shi, H. Wang, Q. Lin, X. Chen, Y. Chen: Ecotox Environ Safe, 67 (2007) 75-81.

[2] A. R. Wadhawan, A. T. Stone, E. J. Bouwer: Environ Sci Technol, 47 (2013) 8220-8228.

[3] B. Dhal, H. N. Thatoi, N. N. Das, B. D. Pandey: J Hazard Mater, 250 (2013) $272-$ 291.

[4] L. F. Feng, W. Qi: J Environ Manag, 92 (2013) 407-18.

[5] L. Zhou, C. Gao, W. J. Xu: App Mater Inter, 2 (2010) 1483-1491.

[6] H. Gao et al: RSC Adv, 5 (2015) 60033-60040.

[7] A. Maleki, B. Hayati, M. Naghizadeh, S. W. Joo: J Ind Eng Chem, 28 (2015) 211216.

[8] A. Adamczuk, D. Kolodynska: Chem Eng J, 274 (2015) 200-212.

[9] L. V. Zhongfei et al: RSC Adv, 5 (2015) 18213-18217.

[10] V. Kumari, M. Sasidharan, A. Bhaumik: Dal Trans, 44 (2015) 1924-1932.

[11] J. Hu, I. M. C. Lo, G. Chen: Langm, 21 (2005) 11173-11179.

[12] S. R. Kanel, J. M. Greneche, H. Choi: Environ Sci Tech, 40 (2006) 2045-2050.

[13] P. Wang, M. C. Irene: Water Res, 43 (2006) 727-3734.

[14] Y. H. Chen, D. Y. Liu, J. F. Lee: Phys Chem Miner, 45 (2018) 907-913.

[15] Y.F. Shena, J. Tang, Z. H. Niea, Y. D. Wanga, Y. Renc, L. Zuo: Sep Purif Technol, 68 (2009) 312-319.

[16] B. S. Damascenoa, A. F. V. Silvab, A. C. V. Araujo: J Environ Chem Eng, 8 (2020) 103994.

[17] X. Liua, J. Tiana, Y. Lia, N. Suna, S. Mia, Y. Xiea, Z. Chen: J Hazard Mater, 373 (2019) 397-407.

[18] T. Shahriari, G. N. Bidhendi, N. Mehrdadi, A. Torabian: Inter J Environ Sci Tech, 11 (2014) 349-356.

[19] E. Demibas, M. Kobya, E. Sentuk, T. Ozkan: Water SA, 30 (2004) 533-539.

[20] V. Miroslava et al, Water treatment technologies for the removal of high-toxicity pollutants, The NATO Science for Peace and Security Series C: Environmental Security book series NAPSC, 2008, 13-17.

[21] K. Y. Foo, B. H. Hameed: Chem Eng J, 156 (2010) 2-10.

[22] S. S. Baral, N. S. Das, R. Pradip: Biochem Eng J, 31 (2006) 216-222.

[23] N. Ayawei et al: J Chem, 1 (2017) 1-11.

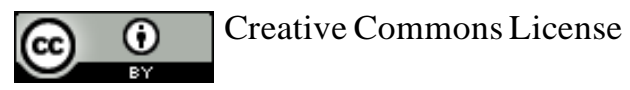

This work is licensed under a Creative Commons Attribution 4.0 International License. 